\title{
TEOREMA REPRESENTASI RIESZ-FRECHET PADA RUANG HILBERT
}

(Riesz-Frechet Representation Theorem in Hilbert Space)

\author{
MOZART W TALAKUA ${ }^{1}$, STENLY JONDRY NANURU ${ }^{2}$ \\ ${ }^{1}$ Staf Jurusan Matematika Fakultas MIPA Universitas Pattimura \\ ${ }^{2}$ Alumni Jurusan Matematika Fakultas MIPA Universitas Pattimura \\ Jl. Ir. M. Putuhena, Kampus Unpatti, Poka-Ambon \\ email: ocat_08@yahoo.com; stenly.nanuru@yahoo.com
}

\begin{abstract}
Hilbert space is a very important idea of the Davids Hilbert invention. In 1907, Riesz and Fréchet developed one of the theorem in Hilbert space called the Riesz-Fréchet representation theorem. This research contains some supporting definitions Banach space, pre-Hilbert spaces, Hilbert spaces, the duality of Banach and Riesz-Fréchet representation theorem. On RieszFréchet representation theorem will be shown that a continuous linear functional that exist in the Hilbert space is an inner product, in other words, there is no continuous linear functional on a Hilbert space except the inner product.
\end{abstract}

Keywords: Banach Spaces, Hilbert Spaces, Norm Space, Pre-Hilbert Spaces, Representation Riesz

\section{PENDAHULUAN}

Ruang Hilbert diperkenalkan oleh David Hilbert (1862-1943), seorang ahli matematika yang sangat terkenal pada generasinya. Penelitian yang dilakukannya menciptakan dasar dari pekerjaannya mengenai "ruang dimensi tak terbatas", yang kemudian disebut dengan ruang Hilbert, suatu konsep yang sangat diperlukan dalam matematika analisis.

Pada tahun 1907, M.R. Frechet (1878-1973), dan F. Riesz (1880-1956) membuktikan bahwa suatu jawaban untuk masalah konvergensi deret Fourier klasik dapat diberikan dalam kaitan dengan Ruang Hilbert $L_{2}(-\pi, \pi)$ (Eberhard Zeidler, 1995). Dalam penelitian ini akan ditunjukkan bahwa hal tersebut merupakan suatu kasus khusus dari suatu hasil abstrak pada sistem ortonormal lengkap dalam ruang Hilbert. Selain itu juga dibahas beberapa sifat atau teorema tentang ruang pre Hilbert dan ruang Hilbert serta pembuktiannya.

\section{TINJAUAN PUSTAKA}

Dalam perkembangan ilmu matematika (sekitar tahun 1909) khususnya dalam bidang analisis tentang ruang Euclides berdimensi- $n$, David Hilbert akhirnya termotivasi oleh analog ruang tersebut kemudian diperluas menjadi ruang dimensi yang tak terbatas dan bersama-sama dengan Schmidt memberikan notasi untuk hasil kali dalam, norma, dan ortogonal. Selanjutnya dalam tesisnya yang berjudul Learning in Hilbert Spaces, Nimit Kumar mencoba menyusun suatu konsep tentang konvergensi barisan dalam ruang bernorma yang mempunyai konsekuensi terhadap barisan Cauchy dan gagasan kelengkapannya (Eberhard Zeidler, 1995).

Kecenderungan untuk mempelajari topik-topik dalam analisis, terutama analisis Fourier, persamaan diferensial, dan persamaan integral, secara abstrak sebagaimana yang dilakukan oleh V. Volterra (18601940), D. Hilbert (1862-1943), E. I. Fredholm (18661927), M. R. Frechet (1878-1973), dan F. Riesz (18801956) pada awal abad ke-20, telah memicu lahirnya sebuah anak-cabang matematika yang kita kenal sekarang sebagai analisis fungsional. Aksioma-aksioma ruang bernorma diperkenalkan pertama kali oleh Riesz ketika ia mempelajari operator di ruang fungsi kontinu $C[a, b]$ pada 1918, namun abstraksinya dirumuskan oleh S. Banach (1892-1945) dalam disertasinya pada 1920. Perluasannya untuk ruang bernorma atas lapangan bilangan kompleks $C$ dikembangkan oleh N. Wiener (1894-1964) pada 1923 (Rudin. W, 1973).

Dengan merujuk pada Zeidler (1995) dan Halmos (1957) yang memberikan pemahaman bahwa setiap ruang 
pre Hilbert atas suatu lapangan adalah juga ruang bernorma atas lapangan tersebut dengan aturan $\|u\|=\langle u, u\rangle^{\frac{1}{2}}$, serta beberapa sifat lain pendukung ruang pre Hilbert dan ruang Hilbert.

Kemudian dengan didukung oleh beberapa literatur lain maka penulis mencoba menyusun sebuah penulisan dengan harapan dapat mudah dipahami walaupun umumnya masih bersifat abstrak.

\section{Definisi 2.1. (Ruang Vektor)}

Sistem $X$ merupakan ruang vektor atas lapangan $F$, terhadap operasi penjumlahan dan pergandaan skalar jika memenuhi aksioma-aksioma di bawah ini :

1. Tertutup.

$$
\left(\forall v_{1}, v_{2} \in X\right) v_{1}+v_{2} \in X
$$

2. Asosiatif.

$$
\left(\forall v_{1}, v_{2}, v_{3} \in X\right)\left(v_{1}+v_{2}\right)+v_{3}=v_{1}+\left(v_{2}+v_{3}\right)
$$

3. Terdapat elemen netral.

$$
(\exists \theta \in X)(\forall v \in X) \theta+v=v+\theta=v
$$

4. Setiap elemen mempunyai invers.

$$
(\forall v \in X)(\exists-v \in X) v+(-v)=-v+v=\theta
$$

5. Komutatif.

$$
\left(\forall v_{1}, v_{2} \in X\right) v_{1}+v_{2}=v_{2}+v_{1}
$$

6. Tertutup terhadap pergandaan skalar.

$$
(\forall v \in X)(\forall \alpha \in F) \alpha v \in X
$$

7. Distributif skalar.

$$
(\forall v \in X)(\forall \alpha, \beta \in F)(\alpha+\beta) v=\alpha v+\beta v
$$

8. Distributif skalar.

$$
\left(\forall v_{1}, v_{2} \in X\right)(\forall \alpha \in F) \alpha\left(v_{1}+v_{2}\right)=\alpha v_{1}+\alpha v_{2}
$$

9. Asosiatif skalar.

$$
(\forall v \in X)(\forall \alpha, \beta \in F)(\alpha \beta) v=\alpha(\beta v)
$$

10. Perkalian dengan skalar 1 .

$$
(\forall v \in X)(\exists 1 \in F) 1 \cdot v=v
$$

selanjutnya ruang vektor $X$ atas lapangan $F$ dinotasikan dengan $X(F)$.

\section{Definisi 2.2. (Himpunan Perentang/Spanning Set)}

Himpunan $\left\{v_{1}, v_{2}, \ldots, v_{n}\right\}$ disebut himpunan perentang untuk $X$ jika dan hanya jika setiap vektor dalam $X$ dapat ditulis sebagai kombinasi linear dari $v_{1}, v_{2}, \ldots, v_{n}$.

\section{Definisi 2.3. (Fungsi Kontinu)}

Misalkan $A \subseteq \mathfrak{R}, f: A \rightarrow \mathfrak{R}$, dan $c \in A$. Fungsi $f$ dikatakan kontinu di titik $c$ jika untuk setiap $\varepsilon>0$ terdapat $\delta>0$ sedemikian sehingga jika $x$ sebarang titik di $A$ sehingga $|x-c|<\delta$, maka $|f(x)-f(c)|<\varepsilon$.

Definisi 2.4. (Batas Atas dan Batas Bawah)

Diberikan himpunan tak kosong $S \subseteq \mathfrak{R}$.

a) Himpunan $S$ dikatakan terbatas ke atas (bounded above) jika terdapat suatu bilangan $u \in \mathfrak{R}$ sedemikian hingga $s \leq u$ untuk semua $s \in S$. Setiap bilangan $u$ seperti ini disebut dengan batas atas (upper bound) dari $S$.

b) Himpunan $S$ dikatakan terbatas ke bawah (bounded below) jika terdapat suatu bilangan $w \in \mathfrak{R}$ sedemikian hingga $w \leq s$ untuk semua $s \in S$. Setiap bilangan $w$ seperti ini disebut dengan batas bawah (lower bound) dari $S$.

c) Suatu himpunan dikatakan terbatas (bounded) jika terbatas ke atas dan terbatas ke bawah. Jika tidak, maka dikatakan tidak terbatas (unbounded).

\section{Definisi 2.5. (Supremum dan Infimum)}

Diberikan himpunan tak kosong $S \subseteq \mathfrak{R}$.

a) Jika $S$ terbatas ke atas, maka suatu bilangan $u$ disebut supremum (batas atas terkecil) dari $S$ jika memenuhi kondisi berikut:

1) $u$ merupakan batas atas $S$, dan

2) jika $v$ adalah sebarang batas atas $S$, maka $u \leq v$. Ditulis $u=\sup S$

b) Jika $S$ terbatas ke bawah, maka suatu bilangan $w$ disebut infimum (batas bawah terbesar) dari $S$ jika memenuhi kondisi berikut:

1) $w$ merupakan batas bawah $S$, dan

2) jika $t$ adalah sebarang batas bawah $S$, maka $t \leq w$. Ditulis $w=\inf S$.

\section{Definisi 2.6. (Barisan Cauchy)}

Barisan bilangan real $X=\left(x_{n}\right)$ disebut barisan Cauchy jika untuk setiap $\varepsilon>0$ terdapat $H(\varepsilon) \in N$ sedemikian hingga untuk setiap $n, m \in N$ dengan $n, m \geq H(\varepsilon)$, berlaku $\left|x_{n}-x_{m}\right|<\varepsilon$.

\section{HASIL DAN PEMBAHASAN}

Pada bagian ini akan dibahas mengenai beberapa definisi dan teorema pendukung pemetaan linier, ruang bernorma, ruang Banach, ruang Hilbert, dan Dualitas Banach yang nantinya akan dipakai pada Teorema Representasi Riesz-Frechet. Sesuai ruang lingkup pembahasan maka lapangan $F$ (field) yang digunakan adalah $\mathfrak{R}$ atau $C$.

\subsection{Pemetaan Linier.}

Definisi 3.1.1. (Devito, 1990).

Diberikan ruang vektor $X$ dan $Y$ atas lapangan $F$. Pemetaan $f: X \rightarrow Y$ dikatakan linier jika untuk setiap $x, y \in X$ dan skalar $\alpha \in F$ berlaku :

(1) $f$ aditif $: f(x+y)=f(x)+f(y)$

(2) $f$ homogen $: f(\alpha x)=\alpha f(x)$

Secara singkat Definisi 3.1.1 ditulis sebagai berikut.

Lemma 3.1.2. (Zaanen, 1997).

Diberikan $X$ dan $Y$ masing-masing ruang vektor atas lapangan $F$. Pemetaan $f: X \rightarrow Y$ dikatakan linier jika dan hanya jika 


$$
f(\alpha x+\beta y)=\alpha f(x)+\beta f(y)
$$

untuk setiap $x, y \in X$ dan skalar $\alpha, \beta \in F$.

\section{Bukti:}

Diambil sebarang $x, y \in X$ dan skalar $\alpha, \beta \in F$. Karena $X$ ruang vektor, jadi $\alpha x \in X, \beta y \in X$ dan $\alpha x+\beta y \in X$.

Syarat perlu:

Karena $f$ linier, menurut Definisi 3.1.1 diperoleh

$$
\begin{aligned}
f(\alpha x+\alpha y) & =f(\alpha x)+f(\beta y) & & (f \text { aditif }) \\
& =\alpha f(x)+\beta f(y) & & (f \text { homogen })
\end{aligned}
$$

Syarat cukup:

1) Untuk $\alpha=\beta=1$,

$$
\begin{aligned}
f(x+y) & =f(1 \cdot x+1 \cdot y) \\
& =1 \cdot f(x)+1 \cdot f(y) \\
& =f(x)+f(y)
\end{aligned}
$$

2) Untuk $\beta=0$,

$$
\begin{aligned}
f(\alpha x) & =f(\alpha x+\theta) \\
& =f(\alpha x+0 \cdot y) \\
& =\alpha f(x)+0 \cdot f(y) \\
& =\alpha f(x)+\bar{\theta} \\
& =\alpha f(x)
\end{aligned}
$$

Dengan $\theta=$ vektor nol di dalam $X$ dan $\bar{\theta}=$ vektor nol di dalam $Y$.

\section{Contoh:}

1) Untuk setiap ruang vektor $X$ atas lapangan $F$;

Pemetaan Nol:

$O: X \rightarrow X$ dengan $O(x)=0$ untuk setiap $x \in X$ merupakan pemetaan linier, juga

Pemetaan Identitas:

$I: X \rightarrow X$ dengan $I(x)=x$ untuk setiap $x \in X$ merupakan pemetaan linier.

2) Jika $X=[a, b]$, yaitu koleksi semua fungsi kontinu dari $[a, b]$ ke $\mathfrak{R}$, maka $C[a, b]$ merupakan ruang vektor atas lapangan $F$ dan

$$
f: x \in C[a, b] \rightarrow f(x)=\int_{a}^{b} x(t) d t
$$

merupakan pemetaan linier dari $C[a, b]$ ke $\mathfrak{R}$, dan $f: x \in C \rightarrow f(x) \in C[a, b]$ dengan

$$
f(x)(t)=\int_{a}^{b} x(u) d u \forall t \in[a, b]
$$

merupakan pemetaan linier.

\subsection{Ruang Bernorma}

Dalam suatu ruang vektor, telah diketahui mengenai konsep panjang dari suatu vektor atau disebut norma. Selanjutnya, suatu ruang $X$ dikatakan ruang bernorma bila definisi berikut dipenuhi.

Definisi 3.2.1. (Royden, 1989).

Diberikan ruang vektor $X$ atas lapangan $F$. a) Fungsi $\|\cdot\|: X \rightarrow \mathfrak{R}$ dinamakan norma bila memenuhi:

$$
\begin{array}{ll}
\left(N_{1}\right) & \|x\| \geq 0 \text { untuk setiap } x \in X \\
\left(N_{2}\right) & \|x\|=0 \Leftrightarrow x=\theta \text { untuk setiap } x \in X \\
\left(N_{3}\right) & \|\alpha x\|=|\alpha|\|x\| \text { untuk setiap } x \in X \text { dan skalar } \\
& \alpha \in F \\
\left(N_{4}\right) & \|x+y\| \leq\|x\|+\|y\| \text { untuk setiap } x, y \in X
\end{array}
$$

b) Ruang linier $X$ yang dilengkapi norma dinamakan ruang bernorma dan ruang bernorma itu ditulis dengan $(X,\|\cdot\|)$ atau $X$ saja jika normanya sudah diketahui.

Norma untuk koleksi semua fungsi linier kontinu disajikan pada definisi berikut ini.

\section{Definisi 3.2.2. (Conway, 1990).}

Jika $X$ dan $Y$ masing-masing ruang bernorma dan fungsi $f: X \rightarrow Y$ linier dan kontinu, didefinisikan bilangan:

$$
\|f\|=\inf \{M:\|f(x)\| \leq M, x \in X \text { dan }\|x\| \leq 1\}
$$

yang disebut norma $f$.

Bentuk lain dari norma $f$ tersebut di atas bisa dinyatakan sebagai

$$
\|f\|=\sup \{\|f(x)\|: x \in X \text { dan }\|x\| \leq 1\} .
$$

Selanjutnya, koleksi semua fungsi linier dan kontinu dari ruang bernorma $X$ ke ruang bernorma $Y$ dinotasikan dengan $L_{c}(X, Y)$.

Bentuk lain dari Definisi 3.2.2 disajikan pada teorema berikut ini.

\section{Teorema 3.2.3. (Conway, 1990).}

Jika $X$ dan $Y$ masing-masing ruang bernorma dan fungsi $f: X \rightarrow Y$ linier dan kontinu maka

$$
\|f\|=\inf \{M \geq 0:\|f(x)\| \leq M\|x\|, x \in X\}
$$

Bukti:

$\|f\|=\sup \{\|f(x)\|: x \in X$ dan $\|x\| \leq 1\}$.

Namakan

$$
\alpha=\|f\|=\inf \{M \geq 0:\|f(x)\| \leq M\|x\|, x \in X\}
$$

Cukup ditunjukan $\|f\| \leq \alpha$ dan $\alpha \leq\|f\|$.

i. $\quad \alpha=\inf \{M \geq 0:\|f(x)\| \leq M\|x\|, x \in X\}$. Jadi untuk setiap $x \in X$ berlaku

$$
\|f(x)\| \leq \alpha\|x\|
$$

Jika $x=\theta$ maka $\|x\|=0 \leq 1$

dan $\|f(x)\|=\|f(\theta)\|=\|\bar{\theta}\|=0 \leq \alpha \cdot 0 \leq \alpha$.

Jika $x \neq \theta$ dibentuk $y=\frac{x}{\|x\|}$ dengan $\|y\| \leq 1$. 
Oleh karena itu $\|f(y)\| \leq \alpha \cdot\|y\| \leq \alpha$. Jadi $\alpha$ batas atas $\{\|f(y)\|: y \in X$ dan $\|y\| \leq 1\}$. Hal ini berakibat

$$
\|f\| \leq \alpha
$$

ii. Sebaliknya $\|f\|=\sup \{\|f(x)\|: x \in X$ dan $\|x\| \leq 1\}$. Jadi untuk setiap $x \in X$ berakibat $\|f(x)\| \leq\|f\|$.

Diambil sebarang $z \in X$. Jika $z=\theta$ jelas berlaku

$$
\|f(z)\|=\|f(\theta)\|=\|\bar{\theta}\|=0 \leq\|f\| \cdot\|\theta\| .
$$

Jika $z \neq \theta$ diperoleh $x=\frac{z}{\|z\|}$ dengan $\|z\| \leq 1$ dan

$$
\begin{aligned}
& \|f(x)\| \leq\|f\| . \\
& \left\|f\left(\frac{z}{\|z\|}\right)\right\| \leq\|f\| \Leftrightarrow\|f(z)\| \leq\|f\| \cdot\|z\| \text { dan }\|f\| \text { salah }
\end{aligned}
$$

satu $M$. Jadi diperoleh

$$
\alpha \leq\|f\|
$$

Berdasarkan persamaan (3.2.1) dan (3.2.2) menunjukan bahwa $\alpha=\|f\|$.

\subsection{Ruang Banach}

Berdasarkan bagian sebelumnya setiap konsep, pengertian, serta sifat-sifat ruang metrik berlaku pula pada ruang bernorma. Ruang bernorma sebagai ruang metrik $d$ yang lengkap (setiap barisan Cauchy di $X$ konvergen ke suatu unsur di $X$ ) disebut ruang Banach.

Selanjutnya, ekuivalensi pernyataan suatu fungsi linier kontinu $X$ dengan suatu fungsi linier terbatas $X$ disajikan dalam teorema berikut.

\section{Teorema 3.3.1. (Conway, 1990).}

Diketahui $X$ dan $Y$ masing-masing ruang bernorma. Jika pemetaan $T: X \rightarrow Y$ linier, maka pernyataan berikut ekuivalen;

(I) $T$ kontinu pada $X$.

(II) $T$ kontinu di $x_{0} \in X$

(III) $T$ kontinu di $\theta \in X, \theta$ merupakan vektor nol di dalam $X$.

(IV) $\{\|T(x)\|: x \in X$ dan $\|x\| \leq 1\}$ terbatas.

(V) Terdapat konstanta $M \geq 0$ sehingga $\|T(x)\| \leq M\|x\|$ untuk setiap $x \in X$.

\section{Bukti:}

(I) $\Rightarrow$ (II), cukup jelas, dimana jika $T$ kontinu pada titik $X$ maka $T$ kontinu pada setiap elemen di $X$.

(II) $\Rightarrow$ (III), karena $T$ linier dan $\theta \in X$, maka $T(\theta)=\theta \in Y$. Selanjutnya diambil sebarang barisan $\left\{x_{n}\right\} \subset X$ dan $\left\{x_{n}\right\} \rightarrow \theta$.

Harus ditunjukkan $\left\{T\left(x_{n}\right)\right\} \rightarrow T(\theta)=\bar{\theta}$.

Karena $\left\{x_{n}\right\} \rightarrow \theta$, maka $\left\{x_{n}+x_{0}\right\} \rightarrow \theta+x_{0}=x_{0}$.
Karena $\quad T: X \rightarrow Y$ kontinu di $\quad x_{0} \in \quad X$ maka $\left\{T\left(x_{n}+x_{0}\right)\right\} \rightarrow T\left(x_{0}\right)$ atau $\lim _{x \rightarrow \infty} T\left(x_{n}+x_{0}\right)=T\left(x_{0}\right)$.

Karena diketahui $T$ linier, maka

$$
\begin{aligned}
\lim _{n \rightarrow \infty} T\left(x_{n}+x_{0}\right) & =\lim _{n \rightarrow \infty}\left(T\left(x_{n}\right)+T\left(x_{0}\right)\right) \\
& =\lim _{n \rightarrow \infty} T\left(x_{n}\right)+T\left(x_{0}\right)=T\left(x_{n}\right)+\bar{\theta}
\end{aligned}
$$

Jadi $\lim _{n \rightarrow \infty} T\left(x_{n}\right)=\bar{\theta}=T(\theta)$.

Dengan kata lain $T$ kontinu di $\theta \in X$.

(III) $\Rightarrow$ (IV), diketahui $T$ kontinu di $\theta \in X$. Diandaikan $S=\{\|T(x)\|: x \in X$ dan $\|x\| \leq 1\}$ tak terbatas. Jadi untnuk setiap bilangan asli $n$ terdapat $x_{n} \in X, x_{n} \neq \theta$ dengan sifat $\left\|x_{n}\right\| \leq 1$ dan $\left\|T\left(x_{n}\right)\right\| \geq n$; jadi

$$
\lim _{n \rightarrow \infty} T\left(x_{n}\right)=\infty
$$

Dibentuk $y_{n}=\frac{x_{n}}{n}$ untuk setiap $n$. Jelas $y_{n} \in X$ dan $\left\|y_{n}\right\|=\frac{1}{n}\left\|x_{n}\right\| \leq \frac{1}{n} \quad\left(\right.$ sebab $\left\|x_{n}\right\| \leq 1$ untuk setiap $\left.n\right)$. Jadi $\lim _{n \rightarrow \infty}\left\|y_{n}\right\|=0$ atau $\lim _{n \rightarrow \infty}\left(y_{n}\right)=\theta$.

Menurut hipotesisnya diperoleh

$$
\lim _{n \rightarrow \infty} T\left(y_{n}\right)=T(\theta)=\bar{\theta}
$$

atau

$$
\lim _{n \rightarrow \infty}\left\|T\left(\frac{1}{n} x_{n}\right)\right\|=\lim _{n \rightarrow \infty} \frac{1}{n}\left\|T\left(x_{n}\right)\right\|=\|\bar{\theta}\|=0
$$

yang berakibat

$$
\lim _{n \rightarrow \infty}\left\|T\left(x_{n}\right)\right\|=0
$$

Persamaan (3.3.1) dan (3.3.2) merupakan suatu kontradiksi. Jadi pengandaian salah, yang benar haruslah $T$ terbatas.

$(\mathrm{IV}) \Rightarrow(\mathrm{V})$, menurut hipotesis $\{\|T(y)\|: y \in Y$ dan $\|y\| \leq 1\}$ terbatas. Jadi terdapat bilangan $M \geq 0$ sehingga $\|T(y)\| \leq M$ untuk setiap $y \in X$ dan $\|y\| \leq 1$.

Selanjutnya diambil sebarang $x \in X$, diperoleh:

1. Jika $x=0$, maka $\|x\|=\|\theta\|=0 \leq 1 \quad$ (jelas)

jadi $\|T(x)\|=\|T(\theta)\| \leq M\|x\|$

2. Jika $x \neq \theta$, maka $\|x\| \neq 0$. Diambil $z=\frac{x}{\|x\|} \in X$ dan $\|z\| \leq 1$.

Menurut hipotesisnya

$$
\begin{aligned}
\|T(z)\| \leq M & \Leftrightarrow\left\|\frac{x}{\|x\|}\right\| \leq M \\
& \Leftrightarrow \frac{1}{\|x\|}\|T(x)\| \leq M(\operatorname{sebab} T \text { linier })
\end{aligned}
$$




$$
\Leftrightarrow\|T(x)\| \leq M \cdot\|x\|
$$

Berdasarkan persamaan (3.3.3) dan (3.3.4), terbukti terdapat bilangan $M \geq 0$ sehingga $\|T(x)\| \leq M \cdot\|x\|$ untuk setiap $x \in X$.

(V) $\Rightarrow$ (I), diketahui $T: X \rightarrow Y$ linier dan terdapat bilangan $M \geq 0$ sehingga $\|T(x)\| \leq M \cdot\|x\|$ untuk setiap $x \in X$. Dibuktikan $T$ kontinu pada $X$. Diambil sebarang bilangan $\varepsilon>0$. Apakah dapat ditemukan bilangan $\delta>0$ sehingga jika $x, y \in X, d_{1}(x, y)=\|x-y\|<\delta$ berakibat $d_{2}(T(x), T(y))=\|T(x)-T(y)\|<\varepsilon$.

Dari

$$
\|T(x)-T(y)\|=|| T(x-y)\|\leq M \cdot\| x-y||<(M+1) \cdot\|x-y\|<\varepsilon,
$$

asalkan $d_{1}(x, y)=\|x-y\|<\delta=\frac{\varepsilon}{M+1}$.

Jadi $T$ kontinu pada $X$

Selanjutnya, norma pada suatu ruang pre-hilbert atau ruang hasil kali dalam didefinisikan sebagai berikut.

Definisi 3.3.2. (Maddox, 1970).

Diketahui ruang pre-Hilbert $X$ dan $x \in X$. Norma vektor $x$ dinotasikan dengan $\|x\|$, didefinisikan sebagai bilangan non negatif:

$$
\|x\|=\sqrt{\langle x, x\rangle}
$$

\section{Teorema 3.3.3 ( Kreyszig, 1978 ).}

Jika $X$ suatu ruang pre-Hilbert maka untuk setiap $x, y \in X$ berlaku ketaksamaan Cauchy-Schwartz:

$$
|\langle x, y\rangle| \leq\|x\| \cdot\|y\|
$$

Bukti:

Diambil sebarang dua vektor $x, y \in X$, diperoleh: Jika $y=0$ maka untuk setiap $\lambda \in C$ berlaku:

$$
\begin{aligned}
0 \leq\langle x-\lambda y, x-\lambda y\rangle & =\langle x, x-\lambda x\rangle-\langle\lambda y, x-\lambda y\rangle \\
& =\langle x, x\rangle-\langle x, \lambda y\rangle-\lambda\langle y, x-\lambda y\rangle \\
& =\langle x, x\rangle-\bar{\lambda}\langle x, y\rangle-\lambda\{\langle y, x\rangle-\bar{\lambda}\langle y, y\rangle\}
\end{aligned}
$$

Untuk setiap $\lambda \in C$, dipilih $\bar{\lambda}=\frac{\langle y, x\rangle}{\langle y, y\rangle}$ sehingga persamaan (3.3.5) menjadi

$$
\begin{aligned}
0 & \leq\langle x, x\rangle-\frac{\langle y, x\rangle}{\langle y, y\rangle}\langle x, y\rangle-\lambda\left\{\langle y, x\rangle-\frac{\langle y, x\rangle}{\langle y, y\rangle}\langle y, y\rangle\right\} \\
& =\langle x, x\rangle-\frac{\overline{\langle y, x\rangle}}{\langle y, y\rangle}\langle x, y\rangle-0=\langle x, x\rangle-\frac{|\langle x, y\rangle|^{2}}{\langle y, y\rangle}
\end{aligned}
$$

Jadi

$$
\frac{|\langle x, y\rangle|^{2}}{\langle y, y\rangle} \leq\langle x, x\rangle
$$

dengan kata lain $|\langle x, y\rangle| \leq\langle x, x\rangle^{\frac{1}{2}}\langle y, y\rangle^{\frac{1}{2}}=\|x\|\|y\|$

Untuk melengkapi pembuktian bahwa norma $\|\cdot\|$ mendefinisikan norma di $X_{2}$ tinggal menunjukkan ketaksamaan segitiga saja yang disajikan pada teorema berikut.

\section{Teorema 3.3.4. (Ketaksamaan segitiga) (Kreyszig,} 1978).

Untuk sebarang dua vektor $x$ dan $y$ di dalam ruang preHilbert $X$ selalu berlaku ketaksamaan segitiga, yaitu

$$
\|x+y\| \leq\|x\|+\|y\|
$$

\section{Bukti:}

Diambil sebarang dua vektor $x, y \in X$, diperoleh:

$$
\begin{aligned}
0 \leq\|x+y\|^{2} & =\langle x+y, x+y\rangle \\
& =\langle x, x+y\rangle+\langle y, x+y\rangle \\
& =\langle x, x\rangle+\langle x, y\rangle+\langle y, x\rangle+\langle y, y\rangle \\
& =\langle x, x\rangle+\langle x, y\rangle+\langle\overline{x, y}\rangle+\langle y, y\rangle \\
& =\langle x, x\rangle+2 \operatorname{Re}|\langle x, y\rangle|+\langle y, y\rangle \\
& \leq\langle x, x\rangle+2|\langle x, y\rangle|+\langle y, y\rangle \\
& \leq\|x\|^{2}+2\|x\| \cdot\|y\|+\|y\|^{2} \\
& =(\|x\|+\|y\|)^{2}
\end{aligned}
$$

Dengan kata lain $\|x+y\| \leq\|x\|+\|y\|$

Selanjutnya, perlu diingat bahwa setiap ruang bernorma merupakan ruang metrik. Hubungan antara ruang hasil kali dalam dengan ruang bernorma disajikan pada teorema berikut ini.

\section{Teorema 3.3.5. (Kreyszig, 1978 ).}

Setiap ruang hasil kali dalam atau ruang pre-Hilbert $X$ merupakan ruang bernorma.

Bukti:

Karena $X$ adalah ruang vektor, maka tinggal diperiksa bahwa $\|\cdot\|$ memenuhi sifat-sifat norma. Diambil sebarang $x, y \in X$ dan $\alpha \in F$, diperoleh:

$\left(N_{1}\right) \quad\|x\|^{2}=\langle x, x\rangle \geq 0$, jelas dari Definisi 3.3.2

$\left(N_{2}\right) \quad\|x\|^{2}=\langle x, x\rangle=0 \Leftrightarrow x=0 \quad$ (menurut $\left.I_{4}\right)$

$\left(N_{3}\right) \quad\|\alpha x\|^{2}=\langle\alpha x, \alpha x\rangle=\alpha \bar{\alpha}\langle x, x\rangle=|\alpha|^{2}\langle x, x\rangle=|\alpha|^{2}\|x\|^{2}$ Jadi $\|\alpha x\|=|\alpha|\|x\|$

$\left(N_{4}\right) \quad\|x+y\| \leq\|x\|+\|y\|$ menurut Teorema 3.3.4

Setelah didapat definisi norma pada ruang hasil kali dalam $X$ maka dapat didefinisikan metrik (fungsi jarak), yaitu $d(x, y)=\|x-y\|$ untuk setiap $x, y \in X$. oleh karena itu kekonvergenan dan barisan Cauchy mempunyai tujuan jelas. 


\subsection{Ruang Hilbert}

Misalkan $X$ ruang vektor atas lapangan $F$ dan $(X\langle\cdot, \cdot\rangle)$ merupakan ruang hasil kali dalam, dapat ditunjukan pemetaan $\|\cdot\|: X \rightarrow F$ dimana $\|x\|=\sqrt{\langle x, x\rangle}$ untuk setiap $x \in X$ merupakan suatu ruang bernorma. Apabila ruang bernorma tersebut lengkap dimana setiap barisan Cauchy di $X$ konvergen ke suatu unsur di $X$, maka ruang ini disebut ruang Hilbert. Sehingga dapat disimpulkan bahwa pada dasarnya ruang Hilbert adalah ruang Banach dengan norma yang ditentukan dari ruang hasil kali dalam.

\section{Definisi 3.4.1. (Kreyszig, 1978).}

Ruang hasil kali dalam (ruang pre-Hilbert) $X$ yang lengkap dinamakan ruang Hilbert.

\subsection{Dualitas Banach}

Dual Banach/Ruang Dual dari ruang bernorma $X$ dinotasikan dengan $X^{*}$ yaitu koleksi semua fungsional linier kontinu dari ruang bernorma $X$ ke lapangan $F(C / \mathfrak{R})$. Jadi

$$
X^{*}=\{T: X \rightarrow F \text { fungsional linier kontinu }\}
$$

\section{Teorema 3.5.1. ( Conway, 1990).}

Ruang dual dari ruang bernorma $X$ yaitu $X^{*}$ merupakan ruang Banach.

\section{Bukti:}

Karena $X^{*}=X^{*}=L_{c}(X, F)$ dan lapangan $F$ itu lengkap maka menurut Teorema 3.3.1 maka $X^{*}$ merupakan ruang lengkap atau ruang Banach.

\subsection{Teorema Representasi Riesz-Frechet}

Pada subbab ini akan dibicarakan teorema representasi Riesz-Frechet dari suatu ruang Hilbert yang nantinya akan digunakan untuk mencari ruang dual Banach dari suatu ruang barisan.

Diawali dengan Teorema 3.6.1 dan Lemma 3.6.2, akan ditunjukan bahwa fungsional linier kontinu pada ruang Hilbert $H$ merupakan hasil kali dalam pada $H$, yang dikenal sebagai Teorema Representasi Riesz-Frechet.

\section{Teorema 3.6.1 ( Royden, 1989).}

Jika $X$ ruang pre-Hilbert maka untuk setiap $y \in X$ menentukan dengan tunggal fungsional linier kontinu $f$ dengan rumus:

$$
f(x)=\langle x, y\rangle \quad \text { untuk setiap } x \in X
$$

\section{Bukti:}

(1) Jelas $f$ linier, sebab untuk setiap skalar $\alpha, \beta \in F$ dan dua vektor $x_{1}, x_{2} \in X$ diperoleh:

$$
\begin{aligned}
f\left(\alpha x_{1}+\beta x_{2}\right) & =\left\langle\alpha x_{1}+\beta x_{2}, y\right\rangle \\
& =\left\langle\alpha x_{1}, y\right\rangle+\left\langle\beta x_{2}, y\right\rangle \\
& =\alpha\left\langle x_{1}, y\right\rangle+\beta\left\langle x_{2}, y\right\rangle \\
& =\alpha f\left(x_{1}\right)+\beta f\left(x_{2}\right)
\end{aligned}
$$

(2) Fungsi $f$ kontinu, sebab untuk setiap $x_{1}, x_{2} \in X$ diperoleh:

$$
\begin{aligned}
\left\|f\left(x_{1}\right)-f\left(x_{2}\right)\right\| & =\left|\left\langle x_{1}, y\right\rangle-\left\langle x_{2}, y\right\rangle\right| \\
& =\left|\left\langle x_{1}-x_{2}, y\right\rangle\right| \\
& \leq\left\|x_{1}-x_{2}\right\|\|y\|<\varepsilon
\end{aligned}
$$

Lemma 3.6.2. (Maddox, 1970).

Diketahui ruang Hilbert $H . G \subset H, G \neq H$ sub ruang tertutup. Untuk setiap $h \in H \backslash G$ dan $g \in G$ berlaku $(h-g) \perp G$ atau $\langle h-g, x\rangle=0$ untuk setiap $x \in G$.

\section{Bukti:}

$h \in H \backslash G$ dan $g \in G$ berarti $h-g \neq \theta$. Diandaikan ada $x \in G$ sehingga $\lambda=\langle h-g, x\rangle \neq \theta$. Jadi $x \neq \theta$ (sebab jika $x \neq \theta$ maka $\lambda \neq \theta$ ).

Didefinisikan $h=g+\lambda \frac{x}{\|x\|^{2}}$. Jadi $h \in G$ dan berlaku $\|h-g\| \leq\|h-k\|$ sebab $\|h-g\|=d(h, G)$. Oleh karena itu diperoleh:

$$
\begin{aligned}
\|h-k\|^{2}= & \langle h-k, h-k\rangle \\
= & \left\langle h-g-\lambda \frac{x}{\|x\|^{2}}, h-g-\lambda \frac{x}{\|x\|^{2}}\right\rangle \\
= & \left\langle h-g, h-g-\lambda \frac{x}{\|x\|^{2}}\right\rangle-\frac{\lambda}{\|x\|^{2}}\left\langle h-g-\lambda \frac{x}{\|x\|^{2}}\right\rangle \\
= & \langle h-g, h-g\rangle-\frac{\lambda}{\|x\|^{2}}\langle h-g, x\rangle-\frac{\lambda}{\|x\|^{2}}\langle x, h-g\rangle \\
& -\frac{\lambda}{\|x\|^{2}}\left\langle x, \frac{x}{\|x\|^{2}}\right\rangle \\
= & \langle h-g, h-g\rangle-\frac{\lambda}{\|x\|^{2}} \cdot \lambda-\frac{\lambda}{\|x\|^{2}} \cdot \lambda+\frac{|\lambda|^{2}}{\|x\|^{2}}\langle x, x\rangle \\
= & \|h-g\|^{2}+\frac{|\lambda|^{2}}{\|x\|^{2}} \\
= & \|h-g\|^{2}-\frac{\lambda^{2}}{\|x\|^{2}}-\frac{\lambda^{2}}{\|x\|^{2}}+\frac{\|\left.\lambda\right|^{2}}{\|x\|^{2}}
\end{aligned}
$$

Jadi $\|h-k\|^{2} \leq\|h-g\|^{2}$ atau $\|h-k\| \leq\|h-g\|$, yang bertentangan dengan $\|h-k\| \geq\|h-g\| \quad$, sehingga $\langle h-g, x\rangle=0$ untuk setiap $x \in G$. Jadi $h-g \perp G$

Selanjutnya akan diperlihatkan Teorema Representasi Riesz-Frechet sebagai berikut. 


\section{Teorema 3.6.3. (Teorema Representasi Riesz-Frechet)} (Royden, 1989).

Diberikan ruang Hilbert $H . f \in H^{*} \Leftrightarrow$ terdapat dengan tunggal $y \in H$ sehingga $f(x)=\langle x, y\rangle$ untuk setiap $x \in H$. Dalam hal ini $\|f\|=\|y\|$.

\section{Bukti:}

Syarat cukup:

Diketahui $H$ ruang Hilbert dan untuk semua $x \in H$ terdapat dengan tunggal $y \in H$ sehingga $f(x)=\langle x, y\rangle$. Ditunjukan $f \in H^{*}$. Diambil sebarang $x_{1}, x_{2} \in H$ dan skalar $\alpha, \beta \in F$, diperoleh:

(i)

$$
\begin{aligned}
f\left(\alpha x_{1}+\beta x_{2}\right) & =\left\langle\alpha x_{1}+\beta x_{2}, y\right\rangle \\
& =\left\langle\alpha x_{1}, y\right\rangle+\left\langle\beta x_{2}, y\right\rangle \\
& =\alpha\left\langle x_{1}, y\right\rangle+\beta\left\langle x_{2}, y\right\rangle \\
& =\alpha f\left(x_{1}\right)+\beta f\left(x_{2}\right)
\end{aligned}
$$

dengan kata lain $f$ linier.

(ii)

$$
\begin{aligned}
\left\|f\left(x_{1}\right)-f\left(x_{2}\right)\right\| & =\left|\left\langle x_{1}, y\right\rangle-\left\langle x_{2}, y\right\rangle\right| \\
& =\left|\left\langle x_{1}-x_{2}, y\right\rangle\right| \\
& \leq\left\|x_{1}-x_{2}\right\|\|y\| \mid<\varepsilon
\end{aligned}
$$

Asalkan $\left\|x_{1}-x_{2}\right\|<\delta=\frac{\varepsilon}{\|y\|+1}$

Syarat perlu:

Diambil $G=\operatorname{ker}(f)=\{x \in H \mid f(x)=0\} . G=\operatorname{ker}(f)$ merupakan subruang tertutup di $H$, sebab:

(i) Diambil sebarang $x, y \in G=\operatorname{ker}(f)$ dan skalar $\alpha, \beta \in F$, diperoleh:

$$
\begin{aligned}
f(\alpha x+\beta y) & =f(\alpha x)+f(\beta y) \\
& =\alpha f(x)+\beta f(y) \\
& =\alpha \cdot 0+\beta \cdot 0 \\
& =0
\end{aligned}
$$

Jadi $\alpha x+\beta y \in G=\operatorname{ker}(f)$. Jadi $G$ subruang linier dari $H$.

(ii) Jika $x$ titik limit $G$, maka terdapat barisan $\left\{x_{n}\right\} \subset G$ sehingga $x=\lim _{n \rightarrow \infty} x_{n}$. Karena $f$ kontinu, maka $f(x)=\lim _{n \rightarrow \infty} f\left(x_{n}\right)=\lim _{n \rightarrow \infty} 0=0$. Jadi $x \in G=\operatorname{ker}(f)$.

Dengan kata lain $G$ tertutup.

Selanjutnya, jika $G=H$ dipilih $y=\theta$ maka $f(x)=\langle x, \theta\rangle=0$ untuk setiap $x \in H$. Jika $G \neq H$ maka untuk setiap $h \in H \backslash G$ terdapat $g \in G$ sehingga $z=h-g \perp G$ (menurut Lemma 4.7.2). jelas $z \neq \theta$ sebab $g-h \neq 0$.
Untuk $z$ tersebut didefinisikan:

$S=\{z f(x)-x f(z) \mid x \in H\}$

$f(z f(x)-x f(z))=f(z) \cdot f(x)-f(x) \cdot f(z)=0$.

Jadi $z f(x)-x f(z) \in G$. Jadi $S \subset G$.

Karena $z \perp G$ dan $S \subset G$ maka $z \perp S$. Oleh karena itu untuk setiap $x \in H$ berlaku:

$$
\begin{aligned}
& \langle z f(x)-x f(z), z\rangle=0 \Leftrightarrow\langle z f(x), z\rangle-\langle x f(z), z\rangle=0 \\
& \Leftrightarrow f(x)\langle z, z\rangle-f(z)\langle x, z\rangle=0 \\
& \Leftrightarrow f(x)=\frac{f(z)\langle x, z\rangle}{\langle z, z\rangle}=\left\langle x, \frac{\overline{f(z)} z}{\|z\|^{2}}\right\rangle
\end{aligned}
$$
untuk setiap $x \in H$.

Selanjutnya akan ditunjukan ketunggalan $y$. Diandaikan ada $y_{1}, y_{2} \in H$ sehingga $\left\langle x, y_{1}\right\rangle f(x)=\left\langle x, y_{2}\right\rangle$ untuk setiap $x \in H$, maka

$$
\left\langle x, y_{1}-y_{2}\right\rangle=0 \text { untuk setiap } x \in H \text {. }
$$

Khususnya untuk $x=y_{1}-y_{2}$ diperoleh

$$
\left\langle y_{1}-y_{2}, y_{1}-y_{2}\right\rangle=0
$$

Jadi $y_{1}-y_{2}=0$ atau $y_{1}=y_{2}$.

Selanjutnya akan ditunjukan $\|f\|=\|y\|$

$$
\begin{aligned}
\|f\| & =\sup \{|f(x)|:\|x\| \leq 1\} \\
& =\sup \{\langle x, y\rangle:\|x\| \leq 1\} \\
& \leq \sup \{\|x\| \cdot\|y\|:\|x\| \leq 1\} \leq\|y\|
\end{aligned}
$$

Di pihak lain:

$$
|f(y)|=\langle y, y\rangle=\|y\|^{2}
$$

jadi

$$
\|y\|=\frac{1}{\|y\|}|f(y)|=\left|\frac{f(y)}{\|y\|}\right|=\left|f\left(\frac{y}{\|y\|}\right)\right| \leq\|f\|
$$

Berdasarkan persamaan (3.6.1) dan (3.6.2) diperoleh $\|f\|=\|y\|$

\section{KESIMPULAN}

Dari pembuktian mengenai Teorema Representasi Riesz-Frechet pada Ruang Hilbert di atas, maka dapat dibuat beberapa kesimpulan sebagai berikut :

1. Setiap ruang hasil kali dalam $X$ atas lapangan $F$ juga merupakan ruang bernorma atas $F$ dengan aturan untuk norma $\|x\|=\sqrt{\langle x, x\rangle}$ untuk setiap $x \in X$.

2. Jika $(X\langle\cdot, \cdot\rangle)$ merupakan ruang hasil kali dalam atas lapangan $F$, dapat ditunjukan pemetaan $\|\cdot\|: X \rightarrow F$ dimana $\|x\|=\sqrt{\langle x, x\rangle}$ untuk setiap 
$x \in X$ merupakan suatu ruang bernorma. Apabila ruang bernorma tersebut lengkap, maka ruang ini disebut ruang Hilbert. Hal inilah yang disebut dengan penyempurnaan sifat dari ruang vektor.

3. Ruang Hilbert adalah ruang Banach dengan norma yang ditentukan dari ruang hasil kali dalam.

Teorema Representasi Riesz-Frechet menunjukan bahwa tidak ada fungsional linier kontinu di ruang Hilbert kecuali berupa hasil kali dalam. Teorema ini nantinya akan digunakan untuk mencari ruang dual Banach dari suatu ruang barisan.

\section{DAFTAR PUSTAKA}

Bartle. R.G, Sherbert D.R (2000), Introduction to Real Analysis, Third Edition. John Wiley and Sons, Inc, USA

Conway. J. B. A (1989). Course in Functional Analysis, Second Edition. Springer-Verlag, New York

Devito. C. L (1990). Functional Analysis and Linear Operator Theory. Addison-Wesley publishing Company, New York

Halmos. P. R (1957), Introduction to Hilbert Space and the Theory of Spectral Multiplicity. Second edition, Chelsea, New York

Howard. A (1987). Aljabar Linear Elementer. Erlangga, Jakarta

Kreyszig. E (1978). Introduction Functional Analysis Aplications. John Wiley\& Son, New York

Leon, Steven. J (2001). Aljabar Linear dan Aplikasinya. Erlangga, Jakarta

Maddox. I. J (1970). Element of Funcional Analysis. Cambridge Univ. Press, London

Royden. H. L (1989). Real Analysis (third Edition). Macmillan Publishing Company, New York

Rudin, W (1973). Functional Analysis . Second edition. McGraw-Hill, Inc, United State

Zaanen. A. C (1997). Introduction to Operator Theory in Riesz Spaces. Springer-Verlag, New York

Zeidler. E (1995). Applied Functional Analysis, SpringerVerlag, Inc, New York 